\title{
EL MARXISMO EN EL PENSAMIENTO DE AUGUSTO DEL NOCE
}

\author{
Carlos Daniel Lasa*
}

\section{Resumen}

El presente artículo hace referencia a la importancia que Del Noce ha otorgado al marxismo en la configuración de la historia contemporánea. Para nuestro autor, la forma de la historia contemporánea está determinada por una filosofía que se ba becho mundo, cual es la marxista. La referida filosofía ha operado una reforma epistemológica de la mismísima filosofía consistente en el pasaje de una lógica de la comprensión a una lógica de la revolución. Sin embargo, a juicio de Del Noce, en el materialismo dialéctico anida una esencial contradicción, la cual conducirá a su suicidio apenas se vea aquel cumplido. En efecto, los dos momentos del marxismo, el utópico del reino de la libertad y el politico de la toma del poder, deben escindirse necesariamente, terminado el segundo por absorber al primero. De allí su suicidio y la heterogénesis de sus fines. Vanamente, dos han sido las líneas que han intentado ir más allá de Marx. Aquella que ha pretendido inverare a Marx (Giovanni Gentile) quitándole el materialismo y que ha desembocado, a través de Antonio Gramsci, en la sociedad de la opulencia; y la otra que, despojando al materialismo dialéctico de la dialéctica, ha terminado en el más absoluto relativismo, representado en las denominadas ciencias humanas y sociales.

Palabras clave: Del Noce, Marxismo, Historia contemporánea, Disolución, Sociedad de la opulencia.

\begin{abstract}
This article refers to the importance Del Noce has given to Marxism in the contemporary history settings. To this author, the form of contemporary history is determined by a philosophy that has become world, which is the Marxist. This philosophy has operated an epistemological reform of the very philosophy, consisting in the transformation of the logic of understanding to the logic of the revolution. However, according to Del Noce, in the dialectical materialism nests an essential contradiction, which leads to its suicide once that is accomplished. Indeed, the two moments of Marxism, utopian realm of freedom and the political realm of seizure
\end{abstract}

* Profesor de la Universidad Nacional de Villa María. Investigador del CONICET. Correo electrónico: cdaniel.lasa@gmail.com 
of power, must be necessarily split, ending the second term to absorb the first one. Hence its suicide and heterogenesis its purposes. Unsuccessfully, two thinking trends have been attempted to go beyond Marx. The first one, has tried inverare Marx (Giovanni Gentile) removing materialism that has led, via Antonio Gramsci, in the affluent society. The other, stripping the dialectical materialism of dialectics, has ended in the absolute relativism, represented in the so-called human and social sciences.

Keywords: Del Noce, Marxism, Contemporary History, Dissolution, Society of opulence.

A juicio de Del Noce, la historia contemporánea está atravesada por la génesis, evolución y declinación de la filosofía marxista. Expresa Del Noce:

Pienso, por el contrario, que puede afirmarse que la historia contemporánea, vista en su totalidad es, simultáneamente, la realización y el fracaso del marxismo. Con el agregado de que el marxismo no hubiera podido realizarse más que en el modo preciso en el cual se ha realizado, de modo tal que puede decirse que la confirmación práctica ha sido hecha y lo ha desmentido. (...) Se debe afirmar que la revolución se ha realizado y, a la vez, ha fracasado. Realizado porque, efectivamente, ha cambiado el mundo, determinando en el mismo Occidente cambios intelectuales y morales de enorme envergadura; fracasado porque ha concluido en la más gigantesca heterogénesis ${ }^{1}$ de los fines que jamás se ha tenido en la historia ${ }^{2}$.

Ahora bien, el marxismo no es sino la forma insuperable del racionalismo ${ }^{3}$, y su realización equivale a su suicidio y al advenimiento definitivo del

${ }^{1}$ Del Noce se refiere a la no correspondencia entre la intención de Carlos Marx, cual es la de pasar del reino de la necesidad al reino de la libertad, y la realidad efectual de una sociedad de la opulencia en la cual reinan la planificación y la estandarización.

2 Augusto Del Noce, "Le radice filosófico-politiche dell'ateismo contemporáneo", en Il Nuovo Areopago, 1983, 2, pp. 13-16.

3 Cfr. Augusto Del Noce, Il problema dell'ateismo, Bologna, Il Mulino, 1990, 4a edizione, p. 22. 
nihilismo. Pero cuando Del Noce hace referencia al racionalismo debemos saber el sentido en el que está empleando dicho término. Nuestro filósofo asume el significado que Laporte otorga al mismo en su obra Le Rationalisme de Descartes. Laporte define el término en relación con la religión. En este sentido, la característica del racionalista sería la del rechazo a toda trascendencia: es un refractario a lo sobrenatural. El racionalista considera que la razón no se apoya sobre nada que no sea ella misma: la razón no tiene necesidad de nada para completarse a sí misma. Pero, ¿por qué motivo, para el racionalismo, la razón humana es autoreferente? ¿Qué evidencia o razón hay para establecer a la razón crítica como principio? No encontramos motivo o evidencia alguna. Para Del Noce, el racionalismo tiene, como punto de partida, una opción: de allí su carácter postulatorio. No es una evidencia lo que constituye el principio del racionalismo sino una decisión. Podríamos decir, entonces, que el ego volo es el verdadero fundamento del ego cogito. Y en este sentido es preciso recordar que fue Nietzsche quien advirtió esta sustitución con total claridad.

Hablamos del marxismo y su relación con el racionalismo. Nos referimos luego al racionalismo. Nos queda ahora por determinar el otro polo, el del marxismo. $\mathrm{Y}$ aquí nos cabe la siguiente pregunta: ¿a qué marxismo hace referencia Del Noce? Él no está haciendo referencia a aquella interpretación metodológica o experimental, la cual consiste en querer salvar todo Marx viéndolo sólo desde la categoría de ciencia política. Considerado desde esta categoría, la sustancia del marxismo residiría en el descubrimiento de un método realista de acción social, en una teoría de la revolución. El marxismo posee una verdad objetiva, dentro de los límites de la ciencia política, la cual es, al modo de las proposiciones científicas, verificable por el resultado ${ }^{4}$. Tampoco hace referencia al marxismo como resultado del proceso revisionista al cual algunos autores sometieron a la doctrina, tratando de inverare 5 Marx, intentando salvar la política y la economía marxista de la ruina de su metafísica ${ }^{6}$.

Del Noce entiende que el elemento fundamental del marxismo radica en su filosofía. Marx no es un mero repetidor de Hegel: su grandeza

\footnotetext{
${ }^{4}$ Cfr. Augusto Del Noce, Il problema dell'ateismo, p 217.

${ }^{5}$ Verbo italiano que podemos traducir como «conferir verdad».

${ }^{6} \mathrm{Cfr}$. Il problema dell'ateismo, p. 215.
} 
especulativa consiste en ofrecer una nueva concepción de la filosofía en cuyo seno sea posible la reconciliación perfecta del pensamiento con la realidad. Para Marx, la filosofía hegeliana estaba fundada en una lógica de la comprensión que "teologizaba" lo real. Si bien esta lógica pretendía evitar toda teologización de lo finito, a la postre lo terminaba haciendo ya que se elevaba a categoría suprema una realidad empírica (Estado prusiano). En efecto, en su seno núcleo de comprensión se terminaban identificando, la "filosofía" y la "historia". Por eso, Marx refunda epistemológicamente la filosofia, al sustituir la lógica de la comprensión por la lógica de la transformación, de la revolución. Es interesante recordar esta referencia de Marx:

La solución de las contradicciones teóricas es posible sólo a través de medios prácticos, mediante la energía práctica del hombre. Su resolución no es pues, de ninguna manera, sólo un problema de conocimiento, sino un problema real de la vida, que la filosofía fue incapaz de resolver precisamente porque sólo veía en él un problema puramente teórico ${ }^{7}$.

Esta interpretación de Del Noce es reafirmada por Lukács en Historia y conciencia de clase. Según Lukács:

En este punto precisamente, donde el parentesco entre el materialismo histórico y la filosofía de Hegel aparece, en el problema de la realidad, en la función de la teoría como conocimiento de la realidad por si misma, es preciso atraer la atención, aunque sea en pocas palabras, sobre la línea de ruptura, no menos decisiva, que los separa. Esa línea de ruptura se halla también al nivel del problema de la realidad, del problema de la unidad del proceso histórico. Marx reprocha a Hegel (y aún más a sus sucesores que han retornado cada vez más netamente a Fichte y a Kant) no haber superado realmente la dualidad del pensar y el ser de la teoría y de la praxis, del sujeto y del objeto; reprocha a su dialéctica, en tanto que dialéctica interior real del proceso histórico, ser una simple apariencia; le reprocha no haber superado a Kant justamente en ese punto decisivo; reprocha al conocimiento hegeliano ser simplemente un conocimiento acerca de una materia -en sí misma de esencia extraña- y no una "confesión" de esa materia que es la sociedad humana.

7 Carlos Marx, Manuscritos económica-filosóficos. En Marx y su concepto de bombre por Erich Fromm. México, Fondo de Cultura Económica, 1970, 3ª reimpresión, p. 143. 
"Ya en Hegel -se dice en las frases decisivas de esta crítica-, el espíritu absoluto de la historia tiene sus materiales en la masa, pero sólo tiene su expresión adecuada en la filosofía. El filósofo aparece solamente como el órgano por el cual el espíritu absoluto, que hace la historia, se eleva a la conciencia, después del desarrollo del movimiento, después del hecho. La participación del filósofo en la historia se reduce a esa conciencia a posteriori, pues el espíritu absoluto ejecuta inconcientemente el movimiento real. El filósofo llega, pues, post festum." Para Hegel, "el espíritu absoluto en cuanto espíritu absoluto sólo hace la historia en apariencia (...) En efecto, como el espíritu absoluto sólo a posteriori se eleva a la conciencia en cuanto espíritu creador del mundo, para el filósofo su fabricación de la historia sólo existe en la conciencia, en la opinión y en la representación de los filósofos, en la imaginación especulativa". Esta mitología conceptual del hegelianismo fue eliminada definitivamente por la actividad crítica del joven Marx (...) Sin embargo, el punto de ruptura radica en la realidad. Hegel no fue capaz de llegar hasta las fuerzas verdaderamente motrices de la historia: porque, en la época en que creó su sistema, esas fuerzas no eran todavía bastante visibles; así, se vio forzado a ver en los pueblos y en su conciencia (cuyo sustrato real no pudo ver en su composición heterogénea y lo convirtió en mito como "espíritu del pueblo") los portadores efectivos del desarrollo histórico; porque él seguía cautivo, a pesar de sus grandes esfuerzos en sentido contrario, de las formas platónica y kantiana de pensamiento, de la dualidad del pensar y del ser, de la forma y la materia ${ }^{8}$.

Es importante que podamos descubrir el trasfondo de esta reforma epistemológica de la filosofía: el rechazo de la categoría griega de substancia. Ello puede apreciarse, con toda claridad, en la Tesis VI sobre Feuerbach. Allí, Marx expresa: "Feuerbach diluye la esencia religiosa en la esencia bumana. Pero la esencia humana no es algo abstracto inherente a cada individuo. Es, en su realidad, el conjunto de las relaciones sociales" 9 . Es a partir de esta negación que a Marx le es posible pasar de la lógica de la comprensión a la de la transformación.

${ }^{8}$ Georg Lukács, Historia y conciencia de clase, La Habana, Instituto del Libro, 1979, pp. $50-52$.

${ }^{9}$ Carlos Marx, Tesis VI sobre Feuerbach. En Carlos Marx, Federico Engels. Obras escogidas en dos tomos. Tomo II. Moscú, Ediciones en Lenguas Extranjeras, 1955, p. 427. 
Marx tiene clara conciencia aquello que Giovanni Gentile explicitaría años más tarde. El filósofo de Castelvetrano señalará que existen dos modos de concebir lo real: como existiendo en sí, independientemente de la inteligencia humana, o como realidad inherente al intelecto, es decir, como producto de este último ${ }^{10}$. Una auténtica filosofía de la praxis no puede sino abrazar la segunda concepción, negando de plano toda intuición intelectual que haga referencia una trama ordenada de lo real. El filósofo de la praxis se funda sobre la negación de la contemplación y la afirmación del primado de la acción; por eso su filosofía no es post factum sino ante factum, y tiene como objetivo la construcción de una realidad totalmente otra, la creación de un mundo nuevo sobre la base del rechazo del existente. A propósito de esta filosofía, Eric Voegelin señaló:

El gnosticismo de Hegel era contemplativo. En lugar de abandonar la gnosis restaurando la verdadera contemplación, Marx abandonó la contemplación traduciendo el gnosticismo en acción (...) La enfermedad espiritual marxista, así como la comtiana, consiste en la auto-divinización del hombre y en la auto-salvación del hombre. Un logos intramundano de la conciencia humana es el sustituto del logos trascendente. Aquello que aparecía sobre el plano de los síntomas como antifilosofismo y logofobia debe ser comprendido etiológicamente como la rebelión de la conciencia inmanente contra el orden espiritual del mundo ${ }^{11}$.

Del Noce abunda y profundiza en la formalidad propia de este gnosticismo de los tiempos modernos, que es como decir la era postcristiana:

(...) la gnosis antigua ateiza el mundo (al negar su creación por parte de Dios) en nombre de la trascendencia divina; la postcristiana lo ateiza en nombre de un inmanentismo radical (...) La búsqueda gnóstica se ocupa de las reglas para la liberación del alma del mundo; el inmanentismo postcristiano es, por el contrario, búsqueda de las reglas para la construcción

${ }^{10} \mathrm{Cfr}$. Giovanni Gentile, Sistemi di Logica come teoria del conoscere. Firenze, Le Lettere, 2003, vol. I, $3^{\text {a }}$ edizione riveduta, p. 21.

${ }^{11}$ Eric Voegelin, Dall'Illuminismo alla rivolurione, Roma, Gangemi Editore, 2004, pp. 303-304. 
de un mundo absolutamente nuevo (...) para designar el proceso que ha conducido a los mitos de la modernidad o de la Revolución (cualquiera sea el adjetivo con el que se la quiera especificar: política, científica, tecnológica), como cesura histórica que permitirá el pasaje al "hombre nuevo", no se puede encontrar otro término más allá del de nueva gnosis ${ }^{12}$.

Del Noce destaca que, dentro del nuevo gnosticismo, la forma activista y revolucionaria está destinada a prevalecer sobre la forma contemplativa, y que la forma activista y revolucionaria de la nueva gnosis no busca la verdad sino el poder ${ }^{13}$. Permítasenos citar estas palabras del filósofo italiano que constituyen una síntesis magistral del proceso historizante del marxismo:

El marxismo es ciertamente, bajo este aspecto, un documento decisivo porque encontramos en él, simultáneamente conectados, la afirmación del primado de la acción, el ateísmo y el carácter superhumanístico, y la ruptura definitiva con el cristianismo. Luego, será con el primado de la acción que acontecerá la mediación del pasaje de la filosofía activista de la historia al totalitarismo, el cual realiza la dependencia del intelectual respecto del político. La decadencia de los intelectuales conduce, finalmente, a la sustitución de la verdad por parte de la mentira eficaz, como el último estadio de la experiencia gnóstica degenerada ${ }^{14}$.

El andamiaje especulativo de Marx es equiparable a la estructura de una filosofía antiplatónica que ha quitado definitivamente de su seno todo vestigio de teoría. Su crítica a la idea de Logos es radical: es incuestionable el rechazo a una Razón superior de la cual el hombre participe, de una Razón que permanezca inmutable a través de la historia. Si el hombre, pues, no participa más de la Razón superior a la historia y, consecuentemente, su propio ser es absorbido por la dimensión social (Tesis VI sobre Feuerbach), entonces el pensamiento pierde su carácter revelador para convertirse en

12 Augusto Del Noce, Saggio a la obra de Eric Voegelin titulada La nuova scienza política, Torino, Documenti di Cultura Moderna, 1968, pp. 19-20.

${ }^{13}$ Cfr. ibidem, p. 31.

${ }^{14}$ Ibidem, p. 31. 
pura actividad transformadora de lo real ${ }^{15}$. En la segunda Tesis sobre Feuerbach, Marx expone el nuevo criterio de verdad, producto de su antifilosofía, afirmando que sólo en la praxis puede el hombre probar la verdad, es decir, la realidad y la potencia de su propio pensamiento. Y afirma Del Noce en este sentido: "Y se advierte también cómo la tesis de la inversión de la praxis significa la radical inversión de la ideología platónicoagustiniana: no obro sobre el mundo a partir de la idea presente en mí, sino que mis ideas son la articulación de mi sentido de reacción al mundo"16.

Esta nueva "filosofía" es, para Del Noce, la causa formal de la historia contemporánea. Todos los acontecimientos sucedidos en la contemporaneidad tienen en el marxismo su causa y explicación. Por eso, su interpretación ha sido calificada como "transpolítica". Refiere Del Noce:

El término de interpretación transpolítica fue usado por Renzo De Felice para designar aquella investigación -y la referencia era al libro de Nolte y a varios de mis ensayos- que pretenden entender al fascismo a la luz "no sólo de un completo análisis histórico, sino también de una rigurosa problemática filosófica, de modo tal de aprehender su esencia, el significado más íntimo y no perderse en los aspectos secundarios ${ }^{17}$.

Es menester expresar que la historia, para Del Noce, no está determinada, como piensa el marxismo, por los conflictos de clase o, como lo sostendrán otros, por el progreso tecnológico. Estos elementos son propios de la causalidad material de la historia; la causa formal y, en consecuencia, el verdadero motor de la historia, debe buscarse en la

${ }^{15}$ Cfr. Augusto Del Noce, Il problema dell'ateismo, p. 245.

${ }^{16}$ Ibidem, p. 245.

17 Augusto Del Noce, Modernità. Interpretazione transpolitica della storia contemporanea, Brescia, Morcelliana, 2007, p. 59. Ver Renzo De Felice, Le interpretazioni del fascismo, Bari, Laterza, 1976, p. 100. Cfr., además, el análisis de De Felice a la posición de Del Noce y su valoración positiva, pp. 87-88. Refiere De Felice que los escritos de Del Noce sobre el fascismo resultan "bastante estimulantes y ricos en indicaciones y sugerencias metodológicas e interpretativas particulares que hacen de los mismos una de las mayores contribuciones ofrecidas a la interpretación del fenómeno fascista" (pp. 87-88). 
filosofía. Refiere nuestro autor: "La forma, que es el elemento decisivo, depende de la visión filosófica global que ofrece las categorías a través de las cuales el cambio es pensado"18. Consecuentemente, para Del Noce, "(...) la historia contemporánea es la historia de una filosofía que se hace mundo; por eso debe ser considerada como historia filosófica, de igual modo que para la historia medieval se habla de historia religiosa"19. En Il problema dell'ateismo abunda:

Si, en efecto, el pensamiento de Marx es genuinamente filosófico, es necesario tomar a la letra su frase según la cual concepción del mundo es aquella de una filosofía que se transforma en mundo (que se supera en la realización política o encuentra en ésta su verificación) opuesta a aquella de un mundo que se transforma en filosofía; si, pues, la historia contemporánea es la historia de la expansión del marxismo, ella adquiere un carácter nuevo, diverso de toda la historia precedente, sobre todo del Renacimiento en adelante. No es solamente una historia que puede ser comprendida por el filósofo; es una historia becha por el filósofo, porque el valor del pensamiento es, para Marx, el de realizar las condiciones para una acción eficaz para transformar la sociedad y el mundo. La historia contemporánea es, por eso, filosófica ${ }^{20}$.

Como muy acertadamente lo señala Lorenzo Ramella, para Del Noce existe una unidad perfecta, como nunca antes había acontecido, entre filosofía, filosofía de la política e historia contemporánea ${ }^{21}$. En síntesis, para Del Noce, la potencia del marxismo radica en su capacidad tanto para condicionar la lógica de los acontecimientos históricos, como para convertirse en un factor fundamental ordenado a dominar los fenómenos culturales y morales que se derivan del propio marxismo.

La unión, en Marx, de "revolución” y "ateísmo" permite definir la historia contemporánea como la expansión mundial del ateísmo. De allí que,

18 Ibidem, pp. 64-65.

19 Ibidem, p. 65.

${ }^{20}$ Del Noce, Il problema dell'ateismo, p. 128.

21 Cfr. Lorenzo Ramella, Il pensiero della mediazione. Augusto Del Noce interprete dell'attualismo, Milano, Vita e Pensiero, 2008, p. 270. 
para Del Noce, la génesis del ateísmo contemporáneo no deba ser buscada en el ámbito científico sino en el filosófico-político. $\mathrm{Y}$ aunque parezca contradictorio, es importante destacar que la revolución en Marx no tiene sólo un significado filosófico sino también teológico. En efecto, para Marx, la revolución representa un salto cualitativo hacia una condición completamente transfigurada de la humanidad, que tiene su raíz ontológica en la negación de la naturaleza inmutable del hombre. La revolución "y no Cristo" es el único medio autorizado para cumplir la obra redentora de la humanidad luego de que el problema del mal fue transferido del plano teológico al sociológico.

Para Del Noce, el ateísmo de Marx constituye el motor de la revolución ya que permite, por un lado, la negación de la esencia del hombre $\mathrm{y}$, en consecuencia, el corte con todo vínculo que la haga partícipe de la vida divina, y por otro lado, la transposición horizontal de la Ciudad de Dios, situándola no ya en Dios sino en la historia misma: una nueva ciudad sin clases que se concretará y desarrollará, en un próximo futuro, en el devenir inmanente. Señala Del Noce:

(...) el rasgo esencial de la inmanentización del eschaton cristiano es el pasaje a la idea mediante la cual el hombre es capaz de autorredención, lo que equivale a decir, conseguir la salvación mediante la acción; es la convicción por medio de la cual el advenimiento del reino de la perfección sobre la tierra se cumplirá por efecto de la iniciativa humana ${ }^{22}$.

Para nuestro autor, si bien la filosofía marxista se cristaliza en la praxis, sin embargo se niega como filosofía. En la tesis XI de Marx sobre Feuerbach, la filosofía ha sido desfondada y, como lógica consecuencia, toda instancia verdadera a partir de la cual medir el devenir histórico se ha borrado. De allí que la revolución emprendida por Marx se caracterice por ser una revolución sin verdad. La causa de esta realidad se encuentra, a juicio de Del Noce, en la contradicción intrínseca que anida, en la filosofía marxista, entre el "materialismo histórico" y el "materialismo dialéctico". Esta contradicción ya había sido advertida por Giovanni Gentile en su escrito

22 Del Noce, Saggio a La nuova scienza politica, p. 20. 
juvenil sobre la filosofía de Marx. Allí, Gentile expresaba que hablar de materialismo histórico es una contradicción en los términos. Señala Gentile:

Pero, ¿qué clase de materialismo es éste? Como todo materialismo no puede reconocer como real más que aquello sensible; pero este sensible, que es estático para todo otro materialismo, para él es dinámico, está en un perpetuo fieri; de allí su nombre de materialismo bistórico. $\mathrm{Y}$ he aquí que este materialismo, por ser histórico, está obligado a negar en su construcción especulativa su propio fundamento: por un lado, no deja que exista otra realidad fuera de la sensible; pero, por el otro, debe refutar los caracteres esenciales de toda intuición materialista como, por ejemplo, la concepción atomista de la sociedad, y el mismo naturalismo. Éste, en suma, es un materialismo que, por ser histórico, no es más materialismo. Una intrínseca, profunda e insanable contradicción lo asalta ${ }^{23}$.

Para Gentile, el pensamiento tiene prioridad absoluta sobre todo, y es de su seno de donde surge la filosofía marxista. Sólo el pensamiento es dialéctico. Señala Gentile: "Y, en efecto, siendo el pensamiento esencialmente unidad, relación, nexo, y no siendo dado por la experiencia este nexo, la luz y evidencia no puede brotar más que del pensamiento: es el pensamiento mismo" 24 .

Con la asunción de la "instancia política" como valor último hacen su epifanía, a juicio de Del Noce, las más variadas formas de totalitarismo. Como ya lo analizamos, para Marx el hombre mantiene una relación constitutiva con la sociedad. Se es hombre como producto de una determinada situación histórica. Para el marxismo no puede hablarse de "naturaleza humana" como de una realidad existente previa a su desarrollo. No existe una naturaleza humana anterior a las relaciones sociales, sino que son estas últimas las que van configurando lo que el hombre vaya a ser. En realidad no podríamos hablar de "hombre", ya que las diversas configuraciones históricas dan lugar a "hombres" que nada tienen en común entre sí. El hombre social se da su propia naturaleza: es un proceso de autocreación y de autotransformación. Entendido en estos términos, el

${ }^{23}$ Giovanni Gentile, La filosofia di Marx, Firenze, Le Lettere, 2003, p. 161.

${ }^{24}$ Ibidem, p. 147. 
marxismo se presenta como la unidad de ética y política, la indistinción entre exterioridad e interioridad. La ética es absorbida, definitivamente, por la política. Las acciones de los hombres ya no pueden ser medidas por una Verdad eterna sino por la praxis política. El intellectus mismo ha sido también absorbido por la ratio. Y la ratio no es sino instrumental: ella busca determinar los medios adecuados para alcanzar los fines que el propio hombre social se otorgue. La verdad, en consecuencia, no será ya ni aletheia $\mathrm{ni}$ adaequatio sino verificación experimental que se opera en la transformación misma de lo tangible. La filosofía de Marx, entonces, verificará su verdad en el momento mismo en que la revolución se efectivice. El marxismo establece como criterio último de verdad el "resultado histórico", es decir, la plasmación de la revolución, no como idea sino como hecho real de la desaparición de las clases y la unificación mundial25. Por ello el cumplimiento de la revolución marxista coincidirá, según Del Noce, con su suicidio y con el reinado absoluto del nihilismo.

Hay un elemento que, para Augusto Del Noce, constituye la clave del entero pensamiento de Marx: el ateísmo. La filosofía de Marx se configura a partir de una "opción": el rechazo de toda dependencia del hombre. De allí la negación del logos, de la teoría como contemplación, del concepto de substancia. Refiere Marx:

Un ser no se considera independiente si no es dueño de sí mismo y sólo es dueño de sí mismo cuando su existencia se debe a sí mismo. Un hombre que vive en favor de otro se considera un ser dependiente. Pero vivo totalmente del favor de otra persona cuando le debo no sólo la conservación de mi vida sino también su creación; cuando esa persona es su fuente (...) Pero como, para el hombre socialista, el total de lo que se llama historia del mundo no es más que la creación del hombre por el trabajo humano y el surgimiento de la naturaleza para el hombre, éste tiene, pues, la prueba evidente e irrefutable de su autocreación, de sus propios origenes (...) El comunismo es la fase de la negación de la negación y, en consecuencia, para la siguiente etapa del desarrollo histórico, un factor real y necesario en la emancipación y rehabilitación del hombre ${ }^{26}$.

${ }^{25}$ Cfr. Del Noce, Il problema dell'ateismo, p. 127.

${ }^{26}$ Carlos Marx, Manuscritos económico-filosóficos, op. cit., III, 6, pp. 146 y 148. 
Para Marx, como puede advertirse, las ideas de "Dios" y de "libertad" son contradictorias y excluyentes. Si Dios no existe, es la humanidad la que se autocrea. Esta operación de Marx es comentada por Del Noce en estos términos: "Lo que sorprende en este pasaje es la total subordinación de la metafísica a la axiología; la afirmación según la cual Dios no debe ser precede a la de que Dios no es, y tal es el único argumento aducido (...)"27.

Sobre esta cuestión se pueden advertir diferencias importantes entre Feuerbach y Marx. Feuerbach piensa que la religión es una alienación que brota de la naturaleza humana y, por lo tanto, es un fenómeno constante. Para Marx, por el contrario, la alienación es producto de un tiempo histórico determinado. Y como las ideas son el reflejo de ese mundo socioeconómico, entonces será menester cambiar las condiciones socioeconómicas para que la alienación desaparezca. En este sentido, habrá de venir, en un futuro no muy lejano, una sociedad en la que el problema de Dios haya desaparecido definitivamente. La revolución marxista promete, precisamente, la desaparición de toda forma de alienación, lo cual equivale a la muerte definitiva de Dios. La revolución se configura como el pasaje del reino de la necesidad -equivalente al orden del ser, al de la libertad-, a un orden completamente nuevo fundado sobre la filosofía de la praxis o del devenir. Pero, ¿cómo será ese reino de la libertad prometido por Marx? Del Noce nos da la siguiente respuesta:

La revolución representa el salto cualitativo hacia una condición completamente transfigurada de la humanidad (es por eso que Marx insiste tanto en la negación de una realidad inmutable del hombre). No podemos representárnosla más que a través de negaciones que son siempre negaciones de la dependencia: es decir, será realizado el eritis sicut Dii. En consecuencia, sociedad sin Estado y sin clases. Pero, calcanzamos a representarnos, aun con la imaginación, una sociedad sin Estado, de modo tal que los conflictos estén totalmente ausentes? (...) En realidad, la forma del pensamiento revolucionario nos empuja a ir más allá de los razonamientos inspirados en el sentido común; a través de la lucha revolucionaria se forjaría una humanidad del todo nueva. ¿Cuál? ¿Se trataría de una suerte de persona colectiva en la cual sean absorbidas las conciencias individuales? Ciertos indicios lo llevarían a pensar. De cualquier forma, limitémonos a reconocer

${ }^{27}$ Augusto Del Noce, ¿Ocaso o Eclipse de los Valores tradicionales?, p. 146. 
que en la lógica del pensamiento revolucionario no se puede representar directamente el resultado de la revolución en relación a la mutación que cualitativamente conlleva. Es natural que, dada nuestra condición actual, no podamos representarnos positivamente una humanidad escindida de toda dependencia ${ }^{28}$.

Ahora bien, para Del Noce, la revolución marxista es llevada a su cumplimiento total por Antonio Gramsci. Gramsci heredó el marxismo resultante de la acción de inverare Marx llevada a cabo por Gentile. Gentile, por eso, brindó a Gramsci la filosofía actualista, es decir, la auténtica filosofía de la praxis. Lo curioso del caso es que fue Gramsci -y no Gentile-, el discípulo más fiel a la misma. En efecto, Gramsci asumió la categoría más acorde a la filosofía de la praxis. la de revolución total. No así Gentile, quien ideó, de un modo para nada coherente, la categoría de risorgimento. Del Noce observa que el cumplimiento total de la revolución marxista de la mano de Antonio Gramsci, coincide con el suicidio de la misma. Veamos, entonces, cómo acontece este suicidio. ¿Cómo se concreta el pasaje de la revolución gramsciano-marxista a la sociedad opulenta?

Para Del Noce, el cumplimiento del marxismo, paradójicamente, equivale a su disolución. Refiere Del Noce:

(...) el marxismo es, bajo este aspecto, la mayor conciliación de opuestos que haya acontecido en la historia del pensamiento. El utopismo llevado al grado máximo, se concilia, por este motivo, con el extremo realismo político; la forma más radical del ateísmo con la que podría ser llamada la última gran religión (...); la unidad de materialismo y de dialéctica, llevados, tanto el uno como el otro, a su máximo nivel (...) Pero, ¿qué ha sucedido durante el proceso de su realización? El momento utópico ha desaparecido, y ha permanecido el realismo político que ha dado origen a aquella novedad que es el totalitarismo (...) El momento religioso, que se confundía con el

28 Augusto Del Noce, I caratteri generali del pensiero politico contemporaneo, Milano, Giuffrè, 1972, pp. 45-46. 
utópico, en razón de la transposición que de la que se hablado, igualmentc ha desaparecido ${ }^{29}$.

Ciertamente, el pensamiento revolucionario de Marx se caracteriza por el intento de mantener dos instancias que, en su realización, deben escindirse necesariamente. El momento utópico, religioso, no puede permanecer cuando el momento del realismo político que implica, sí o sí, la toma del poder, se absolutiza y termina absorbiendo dentro de sí a la instancia ética. En realidad, el marxismo, en lugar de dar paso a una futura sociedad sin clases en la que la libertad queda consagrada, genera, en verdad, una sociedad nihilista y opulenta.

Advierte Del Noce que en Gentile reside una ambigüedad, la cual da lugar a dos versiones del actualismo. La misma no es otra que su posición respecto a la relación entre filosofía y religión. Existen dos valoraciones de la religión en Gentile: por un lado, concibe la religión como un momento ideal absoluto que contiene en forma mítica la misma verdad filosófica; por otro lado, la concibe como la oposición del objeto al sujeto considerada como la negación de este último. Antonio Gramsci asume esta segunda visión. Por lo tanto, para Gramsci, la humanidad se libera pasando de una concepción trascendente a una inmanente. De este modo, se creará una unidad dialética que cancelará las clases sociales, manteniendo otra dialéctica opositiva entre modernidad (inmanentismo) y tradición (religión). Se tienen, en consecuencia, dos interpretaciones del actualismo. La gentiliana, que asume la categoría de "resurgimiento", esto es, una disposición romántico-católica sui generis; y la gramsciana, iluminista, que asume una visión revolucionaria del actualismo.

Cuando Gramsci piensa en la revolución, está teorizando en términos de reforma intelectual y moral que debe alcanzar no sólo a los intelectuales sino también a los simples. Esta inversión estará garantizada por un organismo unitario e históricamente eficaz que hará que los intelectuales y los simples tengan una misma cosmovisión. Refiere Gramsci:

${ }^{29}$ Augusto Del Noce, "Le radice filosófico-politiche dell'ateismo contemporáneo", en Il Nuovo Areopago, n. 2, 1983, p. 16. 
La posición de la filosofía de la praxis es antitética a la católica: la filosofía de la praxis no tiende a mantener a los "simples" en su filosofía primitiva del sentido común sino, por el contrario, los conduce hacia una concepción superior de la vida. Se afirma la exigencia del contacto entre intelectuales y simples, no para limitar la actividad científica y mantener la unidad al bajo nivel de las masas, sino para construir un bloque intelectual-moral que haga posible un progreso intelectual de masas y no sólo para pocos grupos intelectuales ${ }^{30}$.

La idea de "revolución" está unida, en Gramsci, a la de begemonía. Hegemonía es una unidad intelectual y una ética conformes a una concepción de lo real que ha superado el sentido común y ha devenido "crítica". Esto permite la unidad del bloque social. ¿Cómo mantenerla? Mediante la discriminación de las preguntas. Dominar el sentido común controlando tanto la escuela como la cultura para que no reafloren las preguntas metafísicas tradicionales. Refiere Del Noce:

La unidad del bloque histórico-social sería alcanzada a través de la prevalencia de la coerción sobre el consenso, obtenido a través de una discriminación de las preguntas, prohibiendo aquellas que los intérpretes de la ideología, o sea los intelectuales orgánicos, definen como "reaccionarias". O mejor, a través de la creación -a la cual se llega a través del dominio de la cultura y de la escuela- de un nuevo "sentido común", en el cual no reaparezcan más las preguntas metafísicas tradicionales (...) el conformismo del pasado era un conformismo de las respuestas, mientras que el nuevo resulta de una discriminación de las preguntas para la cual las preguntas indiscretas deben ser estigmatizadas al modo de ser consideradas expresiones de "tradicionalismo", de "espíritu conservador", "reaccionario", "antimoderno" o, a veces, cuando el exceso de mal gusto alcanza el límite, de "fascista"; se llega a la situación en la cual el sujeto mismo se las prohíbe como "inmorales", hasta llegar a que estas preguntas, por el proceso del hábito, o en virtud de la enseñanza, no surjan más. Para las preguntas racionales, en efecto, no sucede lo mismo que para los instintos que, reprimidos, vuelven a aflorar; aquellas, por el contrario, pueden desaparecer

30 Antonio Gramsci. Quaderni del carcere. Volume secondo. Edizione critica dell'Istituto Gramsci. A cura de Valentino Gerratana. "Appunti per una introduzione e un avviamento allo studio della filosofía y della storia della cultura", Quaderno II, 12, 16, p. 1384. 
del todo. El disenso es declarado imposible, no por vías físicas, sino por vías pedagógicas. Es en su transposición a lo "moral" que el totalitarismo alcanza su forma más pura ${ }^{31}$.

Esta revolución gramsciana, a juicio de Del Noce, ha disuelto la filosofía en ideología, esto es, ha operado el reemplazo de la búsqueda del conocimiento por la conquista del poder. La ideología, refractaria a la búsqueda de la verdad, es concebida como instrumento de acción política. La idea de modernidad es una categoría central en el pensamiento de Gramsci; de allí que en él se registre la recuperación de la disposición espiritual iluminista: la lucha de la modernidad contra la tradición. La derivación importante de esto, nos advierte Del Noce, es la noción de modernidad ligada a una cierta idea de burguesía. La recomprensión iluminista del marxismo conduce a la alianza con la burguesía "nueva" y anticristiana, fundamentalmente, en la cual pensaba Gramsci. Cuando Gramsci delinea la revolución, piensa en la modernización del país, que es equivalente a la disociación completa del espíritu burgués del cristianismo, y por eso, la total laicización de las costumbres y de la moral.

Luego de las consideraciones precedentes, Del Noce se pregunta acerca del resultado de la revolución gramsciana. En realidad no se ha operado el pasaje del reino de la necesidad al reino de la libertad anunciado, sino que se ha estructurado un mundo en el que reinan la incredulidad y la desvalorización del orden ideal existente. Si bien la sociedad fue descristianizada, sin embargo la cristalización a la que se aspiraba no fue realizada tal como se ha había proyectado. A juicio de Del Noce, el resultado ha sido el advenimiento de la burguesía en estado puro. Debemos tener presente, por un lado, que Gramsci operó un reemplazo: la oposición proletariado-capitalismo burgués por la antinomia fascismo-antifascismo y, por otro lado, distinguió la existencia de una burguesía industrial, progresista, de aquella otra burguesía conservadora, propia del mundo agrario e inmobiliario. Entre ambas formas de burguesía, Gramsci optará por la primera, llegando a constituir una alianza con la misma. El resultado,

31 Augusto Del Noce. Il suicidio della rivoluzione. Milano, Rusconi, 1992, scconda edizione, 319-320. 
para Del Noce, no es otro que la existencia de un gramscismo convertido en instrumento de poder de esa nueva e iluminada clase capitalista-burguesa.

En definitiva, la nueva vía al socialismo no significó más que la transición del viejo al nuevo capitalismo. Gramsci contribuyó, sin más ni más, a la existencia de la actual sociedad opulenta. Ésta ha borrado de sí el misterio y la cualidad, sustituyéndolos por los puros datos mensurables, cuantitativos. La única moral de esta sociedad del bienestar se equipara a la saciedad e incremento de la vitalidad. La unidad de los simples y de los intelectuales ha terminado realizándose por medio de una mentalidad instrumentalista-eficientista. El sociologismo y el positivismo constituyen la fuente del relativismo absoluto que se erige en el alma de esta sociedad opulenta. Ésta ha procurado la caída y la sustitución, como jamás antes se había registrado en la historia de Occidente, de la idea de verdad. En esta sociedad, nos dirá Del Noce, se ha alcanzado el polo opuesto del platonismo: la afirmación del primado del alma concupiscible o la reducción del hombre al alma concupiscible ${ }^{32}$.

La pluma de Del Noce ha puesto de manifiesto los dos procesos que ha seguido la descomposición del marxismo en los países comunistas y en los países occidentales. En los países comunistas, el marxismo ha abonado por completo el momento utópico del marxismo para darle absoluta hegemonía al momento de la toma y mantenimiento del poder político. En los países occidentales, la descomposición del marxismo se ha cristalizado de dos maneras, las cuales, de por sí, han determinado fuertemente a la cultura. Por una parte tenemos aquel marxismo, producto del inveramento de Gentile y Gramsci, el cual consistió en abandonar el materialismo de Marx y asumir, al mismo tiempo, la dialéctica. Éste ha conducido a la instauración de una filosofía de la praxis, que se manifiesta en su máxima expresión y coherencia y, por otra parte, ha derivado en el reinado del nihilismo y en la instauración de la sociedad de la opulencia, tal cual la hemos descrito precedentemente. Por otra parte tenemos aquella operación consistente en la negación de la dialéctica y en la asunción del momento materialista del marxismo. Esta vía ha desembocado en un extremo relativismo, el cual ha terminado fagocitando toda verdad, incluyendo a la del mismo marxismo.

${ }^{32}$ Cfr. Del Noce, ¿Ocaso o Eclipse de los Valores tradicionales?, p. 193. 
Abandonada la dialéctica, resulta imposible pensar en términos de totalidad, y por eso, serán las ciencias humanas las que hegemonicen el actual conocimiento. El positivismo vuelve a hacer su epifanía y, junto a él, un materialismo que invade toda nuestra civilización y signa su resultado nihilista más craso.

Recibido: 09/2010; aceptado: 11/2010. 